Please do not remove this page

RMIT

UNIVERSITY

\title{
Implementing RDA in a time of change: RDA and system migration at RMIT University
}

Parent, Melissa

https://researchrepository.rmit.edu.au/esploro/outputs/9921862243101341/filesAndLinks?institution=61RMIT_INST\&index=null

Parent, M. (2014). Implementing RDA in a time of change: RDA and system migration at RMIT University. Cataloging and Classification Quarterly, 52(6-7), 775-796. https://doi.org/10.1080/01639374.2014.889058 Document Version: Accepted Manuscript

Published Version: https://doi.org/10.1080/01639374.2014.889058

Repository homepage: https://researchrepository.rmit.edu.au

(C) The author

Downloaded On 2023/04/26 20:31:12 +1000

Please do not remove this page 
Thank you for downloading this document from the RMIT Research Repository.

The RMIT Research Repository is an open access database showcasing the research outputs of RMIT University researchers.

RMIT Research Repository: http://researchbank.rmit.edu.au/

\section{Citation:}

Parent, M 2014, 'Implementing RDA in a time of change: RDA and system migration at RMIT University', Cataloging and Classification Quarterly, vol. 52, no. 6-7, pp. 775-796.

See this record in the RMIT Research Repository at:

http://researchbank.rmit.edu.au/view/rmit:24831

Version: Accepted Manuscript

Copyright Statement: (c) The author

Link to Published Version:

http://dx.doi.org/10.1080/01639374.2014.889058 
This is an Accepted Manuscript of an article published by Taylor \& Francis in Cataloging \& Classification Quarterly on 25 August 2014, available online: http://www.tandfonline.com/10.1080/01639374.2014.889058 


\section{IMPLEMENTING RDA IN A TIME OF CHANGE: RDA AND SYSTEM \\ MIGRATION AT RMIT UNIVERSITY}

Melissa Parent, RMIT University

This is an Accepted Manuscript of an article published in

Cataloging \& Classification Quarterly on 25 August 2014, available online:

http://www.tandfonline.com/DOI: 10.1080/01639374.2014.889058.

The National Library of Australia was among national libraries who implemented Resource Description and Access (RDA) in early 2013. RMIT University in Melbourne chose to implement with the National Library, despite an upcoming migration from a Voyager ILMS to Alma library services platform. This article describes the experience of RMIT in implementing RDA while also investing resources in a systems change. It addresses staff training, policy development, and processes to automate the conversion of AACR2 records. It includes lessons learned as advice to institutions who have yet to implement RDA.

KEYWORDS Resource Description and Access (RDA), training, cataloging policy, automation, Alma

\section{BACKGROUND}

RMIT University (RMIT) is Australia's largest tertiary institution. The Library serves a population of 57,000 onshore students across three campuses and 
maintains a collection of approximately 750,000 physical items. RMIT contributes bibliographic and holding records to Libraries Australia, the Australian resource-sharing database administered by the National Library of Australia, and is a member of the Council of Australian University Libraries and the Australian Technology Network of Universities.

The Library Resources and Access department (LR\&A) conducts technical services operations from a central location and is divided into two teams. The Monograph team (16 full-time employees plus manager) performs acquisitions work, copy and original monograph and AV cataloging, and end processing. The E-resources and Serials team (11 FTE plus manager) performs electronic resource management tasks, copy cataloging of serials, and database management activities. By a slight majority, most LR\&A team members hold professional librarian qualifications, which in the Australian context means a tertiary qualification at the bachelor, graduate diploma or masters level ${ }^{1}$. The remaining members hold paraprofessional qualifications or equivalent experience. Tasks within each team tend to be allocated according to aptitude and productivity rather than according to a staff member's qualification, and blended roles that include a range of tasks are common. The Library may be somewhat unusual in this respect. More than half of all LR\&A staff have been in the department for twenty or more years.

\section{INTRODUCTION}

In April 2013, RMIT Library chose to implement RDA concurrently with another significant change: migration from a Voyager ILMS to an Alma library 
services platform. LR\&A managers knew that Alma migration would happen in May 2013. They also knew that it would have far-reaching effects on unit operations, and that deferring RDA implementation until Alma effects were subsumed into business as usual operations could push RDA implementation into 2015 or later. Rather than wait until then and enact temporary measures for dealing with the RDA records that catalogers would be certain to encounter, managers chose to implement RDA at a time of operational flux.

When considering the ways in which institutions differ in their staffing, workflows, systems, and working culture, it follows that every RDA implementation will be different. In her 2013 OCLC webinar on RDA implementation ${ }^{2}$, Stalberg describes this phenomenon as '[implementation] mileage may vary', and stresses the fact that there is no perfect implementation. In the same Webinar session, Maurer also highlights the institutional context of any implementation ${ }^{3}$. Some institutions may implement after a period of careful analysis and planning; others with less prior analysis and planning. This article describes the RDA implementation experience of RMIT, which occurred after a short period of planning. The article details the implementation staffing and training process, local RDA policy development, and systems considerations in an Alma-Primo configuration. It includes a section on batch processing to convert AACR2 to RDA records, and offers lessons learned in training and policy development.

\section{STAFFING}


The first set of implementation decisions at RMIT consisted of locally defining the terms of the Library's RDA implementation. A local definition established the implementation's scope and provided a foundation for future decisions. For RMIT University, RDA implementation was initially defined as:

- Original cataloging contributions to the Australian National Bibliographic Database (ANBD) are created according to RDA guidelines.

- Records requiring significant upgrade (pre-publication or minimal level records) are converted to RDA at the time of upgrade.

- Accurate, full-level AACR2 copy is accepted as is.

- AACR2 legacy data would possibly be batch-processed after initial implementation was complete and batch processes designed.

RDA training decisions followed implementation definitions. Many roles in LR\&A are blended roles that involve a mixture of professional and paraprofessional tasks ranging from database maintenance and acquisitions tasks to copy and original cataloging. Given the LR\&A staffing model, RDA training at RMIT could be exclusive (training only original catalogers), inclusive (training copy and original catalogers), or staggered (training first catalogers and then other staff). The exclusive training scenario would involve fewer staff and have less impact on unit operations and was therefore an attractive option. However, an exclusive training scenario would also exacerbate gaps in unit-wide competencies that had already demonstrated adverse effects on the development of efficient and innovative workflows. Considering the unknown future demands that would be made on LR\&A 
workflows, the Alma factor favored inclusive or staggered training scenarios. These scenarios would maximize flexibility in task allocations because more staff would be RDA-ready, albeit with some discrepancies in RDA-readiness among staff if training was rolled out over a longer period as in a staggered training scenario. In the end, the Library chose an inclusive training scenario due to uncertainty over whether staggered training was sustainable.

\section{RDA TRAINING}

One experienced cataloger from the Monographs team received external training in RDA, attending a three-day course presented by the National Library of Australia (NLA) in late 2012. National Library staff, some of whom were also members of the Australian Committee on Cataloguing (ACOC) developed Australia's "RDA Train-the-trainer" course and made all course materials available on the ACOC website ${ }^{4}$. A second staff member from the E-resources and Serials team who had a background in training worked with the Monographs team member to adapt and supplement NLA training materials, and design and deliver a training program.

Training was delivered to small groups of 3-4 learners. The small group design was chosen as a tool for managing the diverse cataloging knowledge and experience of trainees. Each training session introduced and explained information using a PowerPoint presentation, with questions and discussion encouraged throughout the presentation. Participants then logged into the Toolkit and worked through exercises to apply new information and build on previously covered information. The exercise stage allowed for further 
individual or group instruction when required. Although LR\&A staff received unrestricted Toolkit access two months prior to formal training, few had spent time in the Toolkit previously and the first two training sessions included a focus on Toolkit structure and orientation.

Each of the seven training groups received five 90-minute training sessions over a seven-week period. Training in small groups was resource intensive in terms of trainer time but allowed for more tailored training than would have been manageable with a large group. One group, composed entirely of members having original cataloging experience, preferred less instruction, more solo practice with challenging items, and thoughtful discussions on RDA concepts and principles. Another group, composed entirely of members having no original cataloging experience, preferred detailed instruction with immediate practical application and very little theoretical discussion. The remaining groups demonstrated learning preferences between these two. Working with small groups allowed for the alteration of training materials and delivery according to the specific needs of each group.

Training primarily focused on how to use the Toolkit to describe manifestations and record relationships. Follow-up training sessions were required to address work-work relationships in greater detail, and to provide training in cataloging translations and resources in multiple languages. The Library does not practice authority work and hadn't for some time, thus training omitted significant aspects of RDA that other institutions may well cover. Another notable omission in the Library's RDA training in comparison with other library's training programs (see for example Cronin's report on RDA 
testing at implementation at the University of Chicago ${ }^{5}$ and Shieh's report on RDA testing at George Washington University Libraries ${ }^{6}$ ), was structured training in the differences between AACR2 and RDA. Given the mixed cataloging experience of learners, it was felt that formal mention of AACR2 should be minimized. Rather than include differences between AACR2 and RDA in formal training, differences between AACR2 and RDA were covered in pre-training sessions instead, and Adam Schiff's authoritative presentations on this topic ${ }^{7}$ made available.

RDA training at RMIT omitted authorities and AACR2 comparisons but had a strong focus on FRBR (Functional Requirements for Bibliographic Records). This was decided without debate between managers and trainers, all of whom felt that understanding RDA required a solid grounding in the conceptual model upon which it is based. Their decision, though unquestioned and more instinctive than analytic, does have basis in the literature. When the National Library of Australia presented RDA and its advantages for libraries in a 2009 Staff Paper ${ }^{8}$, the FRBR model and its relationship to RDA received significant attention. Hitchens and Symons focus on FRBR theory as it relates to RDA training in their 2009 text that sought to prepare catalogers for upcoming RDA training ${ }^{9}$. Mitchell, analyzing RDA testing case studies ${ }^{10}$ and Loesch surveying RDA literature ${ }^{11}$ also include detailed discussions of FRBR as it relates to RDA.

FRBR terminology and concepts had been introduced to RMIT staff at seminars dating from 2010 , seminars driven by one manager's membership in 
ACOC. Key FRBR terms and concepts were summarized at a final pretraining seminar. During formal RDA training each session began with WEMI practice and discussion using work sets that included a work in different formats, languages, and in adaptations. WEMI practice was extremely challenging in the first two weeks, but with time and practice did become easier for most learners. The conceptual difficulties that WEMI presented for learners were highly individual and irrespective of a staff member's professional qualification or role, with one notable exception: difficulties around the Expression level were not individual but appeared common to most if not all learners.

Due to the fact that all staff received identical FRBR training and there is no control group to compare against, it is difficult to assess whether the FRBR focus helped RMIT staff to better understand RDA than they otherwise would have. The FRBR focus did appear to hasten a shift in the language of cataloging. Trainers were able to rely heavily on FRBR terminology when presenting RDA concepts and guiding learners through the Toolkit, with less obvious confusion from learners as training progressed. Staff members began using FRBR terms and invoking FRBR principles with increasing confidence during training sessions and during peer review. It is possible that the FRBR focus of RDA training at RMIT also facilitated Toolkit orientation and efficiency in using the cataloging tool. Staff initially found it difficult to navigate the structure of the Toolkit and contextualize instructions, using, for example, instructions in Chapter 6 (Identifying Works and Expressions) rather than instructions in Chapter 2 (Identifying Manifestations and Items) when Toolkit 
searches included results from both chapters. As they came to understand the difference between Work, Expression, Manifestation, and Item, these difficulties lessened. Of course, difficulties may also have lessened due to greater familiarity with the Toolkit itself, without staff necessarily making connections between RDA and its FRBR foundations.

Emphasizing FRBR in RDA training had one negative consequence, in that some staff who found the conceptual model difficult to understand expressed uncertainty over their ability to correctly apply RDA. Trainers downplayed the role of FRBR in RDA for these learners, assuring them that knowing the language and how to find what they needed in the Toolkit was enough. But managers and trainers privately wondered if terminology and Toolkit knowhow were in fact sufficient to allow catalogers to appropriately apply RDA. This is a significant question and one that is not yet addressed in the literature. The cataloging community agrees that FRBR is an important part of RDA, but has yet to assess the role of FRBR in catalogers' understanding of RDA and ability to create RDA records. Although aware of the larger unknowns around FRBR and RDA application, trainers put aside theoretical considerations and continued to assure struggling learners that FRBR understanding was nice but not necessary in order to be able to use RDA.

As training progressed, some unexpected realities became clear. First, the boundaries between resource description and encoding were not clear among some staff including those whose current roles included original cataloging. Experienced catalogers expected guidance on punctuation to be embedded in 
RDA guidelines alongside the data elements as is the case in AACR2 part 1, which is based on the General International Standard Bibliographic Description $(\operatorname{ISBD}(\mathrm{G}))$. Punctuation being an integral element of ISBD, AACR2 rules necessarily included punctuation guidelines. Although punctuation is not a required element of RDA description, RDA is intended to be interoperable with ISBD and RDA records continue to be compatible with ISBD display ${ }^{12}$. Appendix $\mathrm{D}$ of the Toolkit contain guidelines on including ISBD punctuation in RDA formulated records, and LC-PCC policy statement 1.7.1 provides specific punctuation guidance for key MARC21 fields when encoding RDA elements using MARC21, a standard whose documentation routinely includes punctuation in examples and in explicit instructions. Given the relationship between ISBD and AACR2, and references to ISBD punctuation in the MARC21 encoding standard that is familiar to most catalogers, it is perhaps understandable that the boundary between RDA description and the punctuation of encoding was unclear. Catalogers who did not understand the resource description/encoding distinction are not unique to RMIT, as Stalberg makes the same observation in her OCLC webinar 'RDA in Context $^{13}$. Institutions who have yet to implement RDA should be prepared to encounter the same phenomenon. In hindsight, the boundaries between description and encoding could have been explored in pre-training seminars.

A second unexpected reality was the importance that some professional catalogers placed on examples over principles. This again echoes Stalberg's observations $^{14}$. Trainers distributed National Library of Australia RDA records and the link to the Program for Cooperative Cataloging Standing Committee 
on Training (PCC-SCT) RDA example records ${ }^{15}$ at the start of training. Staff were also instructed to find their own examples on the ANBD and in the Library of Congress catalog. As staff began creating and reviewing RDA records (a process described in detail below) it became clear that some staff used example records for guidance rather than the Toolkit. That is, rather than consulting RDA principles and guidelines, they relied solely on the work of other catalogers. This was certainly not the case for all staff, many of whom used example records as intended by trainers (as examples of RDA principles in practice). Relying on examples rather than principles was not the desired way for catalogers to learn RDA, but it has proven a difficult habit to break. RMIT has made some progress toward breaking the habit by making extensive use of a peer review process that requires catalogers to cite the Toolkit when providing feedback or justifying decisions made in their own records. Other institutions may take a different approach, or may not recognize example-based cataloging as an issue to be addressed.

\section{PEER REVIEW}

Peer review was an important element of RDA training and implementation at RMIT. It was introduced as soon as learners began to create RDA records for their practice items (in the second week of training) and formally continued until three months past implementation. Peer review was introduced as a way for staff to learn from each other. Trainers were also open about the fact that peer review was intended to enforce use of the Toolkit. The RDA testing and implementation body of literature frequently reports difficulty navigating, using, and interpreting the Toolkit. In his analysis of several RDA testing case 
studies, Erik Mitchell states that RDA testers commonly found it challenging to use the Toolkit, at least until they had gained some familiarity with the cataloging tool ${ }^{16}$. Trainers were eager to have staff spend as much time as possible in the Toolkit to gain familiarity with its structure and become proficient in Toolkit navigation.

During training learners exchanged each of their RDA records with another member of their training group. After implementation, staff continued to vet the majority of their records with a member of their training group until managers assigned strategic peer review pairs. Assigned peer review paired those without prior original cataloging experience with those who had original cataloging experience, taking care to avoid pairings of staff who did not work well together. Additionally, peer review paired catalogers with different strengths, for example pairing efficient and practical catalogers with less productive catalogers who spent time crafting detailed records.

Peer review of each record can be a valuable learning tool during the initial RDA training phase and can be seen as a worthy investment in a successful implementation. Even after formal peer review halted at RMIT, the culture of peer review has persisted and staff openly consult with each other when they encounter difficult or unusual items. After initial training, however, a record-byrecord peer review model as done at RMIT may not be feasible for many institutions. In RMIT's implementation, intensive peer review after training and well into RDA implementation was made possible by workflow disruptions caused by the Library's migration to Alma, which did not go smoothly. Alma is 
a completely new library system design ${ }^{17}$ and uses a conceptual model that has little in common with a client-based Integrated Library Management System (ILMS). Developing new workflows in an unfamiliar environment was challenging and in the early days of Alma migration RDA practice with peer review was something that staff could do while waiting for operations to resume as normal.

Any institution that employs peer review as a training and implementation strategy would do well to bear in mind the experiences of RMIT. Despite the benefits of peer review (building Toolkit familiarity, breaking example-based cataloging habits), it did have drawbacks. These included discomfort in giving and receiving feedback, perception that peer review was at best intrusive and at worst a form of punitive surveillance (as revealed at one tense staff meeting), and some staff being very critical of their peers' cataloging judgment when it differed from their own. Reflecting on the peer review experience, both LR\&A managers concede that it was a valuable component of the Library's RDA implementation. One manager feels that peer review could have been more successful if a culture of peer review had been developed in advance of RDA training and implementation, because learning and applying new guidelines while undergoing a novel peer review process was stressful for some staff. The other manager feels the opposite. In this manager's opinion, RDA implementation was the ideal time to introduce peer review as all staff were new to RDA. Therefore, staff were unable to fall back on greater experience using 'the rules' when receiving feedback perceived as critical, as could have the case if peer reviewing AACR2 records. 


\section{RDA POLICY DEVELOPMENT}

Training and implementation literature frequently cites the development or use of RDA policy. As El-Sherbini ${ }^{18}$ exhaustively details in her RDA: Strategies for Implementation, RDA includes a number of instructions that permit cataloging agency decision-making, including type of description, how to handle transcription elements (transcribe as found on resource OR according to RDA's guidelines on transcription OR according to in-house policies), and how to handle the RDA alternatives, optional omissions, and optional additions that are left to cataloger's judgment. Cronin ${ }^{19}$ adds RDA core element decisions, or whether or not an institution will expand on the RDA core element set when creating its own RDA records. Maurer ${ }^{20}$ flags additional institutional decisions around accepting AACR2 and/or RDA copy, upgrading records, and handling hybrid records. Local policy will therefore be part of any RDA implementation.

Before training and implementation, LR\&A managers were primarily occupied with preparations for migration to Alma and did not have the time to work with trainers to develop local RDA policy. The Library was forced by circumstances to issue very minimal policy at the outset of training and implementation, and develop detailed policies as training and implementation proceeded. The minimal policy at the outset of training considered type of RDA description (descriptive) and RMIT core manifestation-level elements, which included RDA core elements plus two additional elements (copyright date and media 
type) in line with the National Library's policy, accessed through managerial participation in ACOC.

Developing RDA policy as training and implementation proceeded was a task in data analysis, communication, and information organization. RDA trainers tracked hot topics of discussion across training sessions and noted specific questions during one-on-one discussions with learners. One trainer also regularly extracted RDA records and reviewed them in MarcEdit to identify trends or the lack thereof and systematic errors. Notes and observations were gathered in a collaborative document shared with $L R \& A$ managers and supplemented with information to aid in policy decision-making. Information to aid in decision-making was sourced from the rdaaust electronic mailing list administered by the National Library ${ }^{21}$, the RDA mailing list administered by the $\mathrm{JSC}^{22}$, and discussion papers collected on the JSC website ${ }^{23}$. The mailing lists were extremely valuable tools for collecting a variety of reasoned opinions while discussion papers provided a larger context for local policy decisions.

There were many perplexing areas that fueled policy development at RMIT, but one in particular will be highlighted here to illustrate how the challenges of Toolkit structure, which Mitchell describes as not allowing 'linear' use in following cataloging rules" ${ }^{24}$, can have an effect on local RDA policy. Soon after implementation, the trainers became aware that staff were applying various interpretations of RDA guidelines when recording place of publication and publisher's name. To record these elements catalogers must consult RDA 
2.8.1.4, 2.8.2.2, and 2.8.4.2, while bearing in mind the preferred source of information for title proper (which for monographs is the title, as per RDA 2.3.2.2 and 2.2.2.2).

RDA 2.8.1.4 states "Transcribe places of publication and publishers' names as they appear on the source of information". RDA 2.8.2.2 and 2.8.4.2 provide guidance on sources of information for place of publication and publisher's name. RDA 2.8.2.2 instructs catalogers to "Take places of publication from the following sources (in order of preference): a) the same source as the publisher's name (see 2.8.4.2); b) another source within the resource itself (see 2.2.2); c) one of the other sources of information specified at 2.2.4". RDA 2.8.4.2 in turn tells catalogers to 'Take publishers' names from the following sources (in order of preference): a) the same source as the title proper (see 2.3.2.2); b) another source within the resource itself (see 2.2.2); c) one of the other sources of information specified at 2.2.4".

RDA 2.8.1.4 together with 2.8.2.2 and 2.8.4.2 leads to recording the place of publication and publisher's name as found on the title page. Many items, however, do not have all three data elements-title proper, place of publication, publisher's name-on the title page. Further, 2.8.1.4 includes an optional omission ("Omit levels in a corporate hierarchy that are not required to identify the publisher") and RDA 2.8.2.3 tells catalogers: "Record the place of publication by applying the basic instructions at 2.8.1. Include both the local place name (city, town, etc.) and the name of the larger jurisdiction or 
jurisdictions (state, province, etc., and/or country) if present on the source of information."

In RMIT's experience, catalogers found it difficult to apply RDA 2.8 guidelines before the key decision-making instructions at 2.8 were clarified in policy statements. Trainers became aware of cataloger difficulty through discussions with learners and covert observation of peer reviews, and gathered anonymous staff responses to a set of items bearing complex publication details. Figure 1 illustrates the first of five items in the set.

\section{FIGURE 1. COMPLEX PUBLICATION DETAILS}

Title page

$\begin{gathered}\text { Using e-books and e-readers } \\ \text { for adult learning }\end{gathered}$
Sandie Gay - Tina Richardson
Diace

Title page verso

Published by the National Institute of Adult Continuing Education NIACE (England and Wales) 21 De Montfort Street Leicester LE1 7GE

Staff recorded place of publication and publisher's name a number of different ways in their responses.

- Leicester ; National Institute of Adult Continuing Education

- Leicester ; National Institute of Adult Continuing Education (England and Wales)

- Leicester, England; NIACE 
- Leicester, England ; National Institute of Adult Continuing Education

- Liecester, England ; NIACE National Institute of Adult Continuing Education

None of the responses show correct application of RDA guidelines. The third response (supplied in 3 out of 17 responses) is arguably the closet to correct. The third response alone shows correct application of 2.8.4.2 preference (a) and takes the publisher's name from the same source as the title proper (the title page), but does not then correctly apply 2.8.2.2 preference (b) to record the place of publication as found on another source (title page verso) since 2.8.2.2 preference (a) can not be fulfilled by this item. Recording place of publication as 'Liecester, England' is almost correct, but for confusion over the role of 'England' on the title page verso. 'England' is part of the address but not as a jurisdiction and 2.8.2.3 should not applied in order to include 'England' as part of the place of publication. The majority of responses also recorded 'England' as a place name jurisdiction, showing that catalogers were interpreting 2.8.2.3 to mean that a larger place name should be recorded if present regardless of whether or not the name was used as a jurisdiction. Staff received clarification of 2.8 guidelines when they were incorporated into a policy statement on optional omission of names in a corporate hierarchy at RDA 2.8.1.4. Trainers realized that more structured practice navigating and interpreting the relevant portions of RDA 2.8 and more guidance applying 2.8 preferences during formal training could have prevented the necessity for later clarification through policy statements. 
Developing policy as an implementation proceeds may not be an attractive option for institutions that prefer a more measured approach. A develop-asyou go approach to policy did however reveal two beneficial features of the less planned approach at RMIT. First, allowing staff to apply their own judgment revealed where policy was most needed. Where staff questioned or showed disagreement with one another a local policy decision was required. For other areas a policy decision might have been useful but was not immediately needed. Second, allowing (or forcing) catalogers to apply their own judgment in the initial stages of RDA learning and implementation fuelled many discussions on the role of cataloger's judgment in RDA, especially in contrast to the more prescriptive nature of AACR2. As observed by Loesch ${ }^{25}$ in her summary of RDA literature, some staff enjoyed the freedom of being able to apply their own judgment when creating RDA records. Other catalogers expressed discomfort with such freedom and were eager to see clear guidelines established.

\section{RDA AND SYSTEMS}

RDA has brought a number of changes to the MARC data that library systems manipulate. While not an exhaustive listing, these changes include the 264 tag that records production, publication, distribution, manufacture or copyright notice; 33X tags recording content, media and carrier in lieu of a GMD; 34X tags to record carrier characteristics; and $38 \mathrm{X}$ tags recording work and expression characteristics. The MARC standards have also been partly revised to accommodate RDA relationship terms that explicate the relationship between a name and a resource or between one resource and 
another resource. In MARC these relationship terms appear as $\$$ e or $\$ \mathrm{i}$ subfields in name and added entry tags or in linking entry tags.

Although, as noted by Cronin ${ }^{26}$, system support for RDA data varies from vendor to vendor and institutions will have varying control over how their data displays and indexes, all institutions need to make certain decisions about integrating RDA with AACR2 MARC. Chiefly, institutions must decide how to handle AACR2 GMDs versus RDA content, media, and carrier types, and how to handle the relationship terms in RDA records. The use of MARC 260 versus 264 tag will also be a consideration.

During training and the initial stages of RDA implementation, RMIT University ran a Voyager ILMS and OPAC with a Primo discovery layer. Shortly after implementation, the Library would migrate to an Alma-Primo configuration and the discovery layer would become the sole search interface for public services staff and users. Systems considerations therefore focused on RDA in Alma and Primo. After populating the database with a small number of RDA records, the Library found, as expected, that Primo does not require GMDs to meaningfully display and facet search results, and does not display or index content-media-carrier terms. Primo displays 264 field information and relationship terms on name access points. It does not display resourceresource relationship terms found in $7 X X \$$ i subfields. Figures 2 and 3 below show an Alma RDA record and its display in Primo. 


\section{FIGURE 2. RDA IN ALMA}

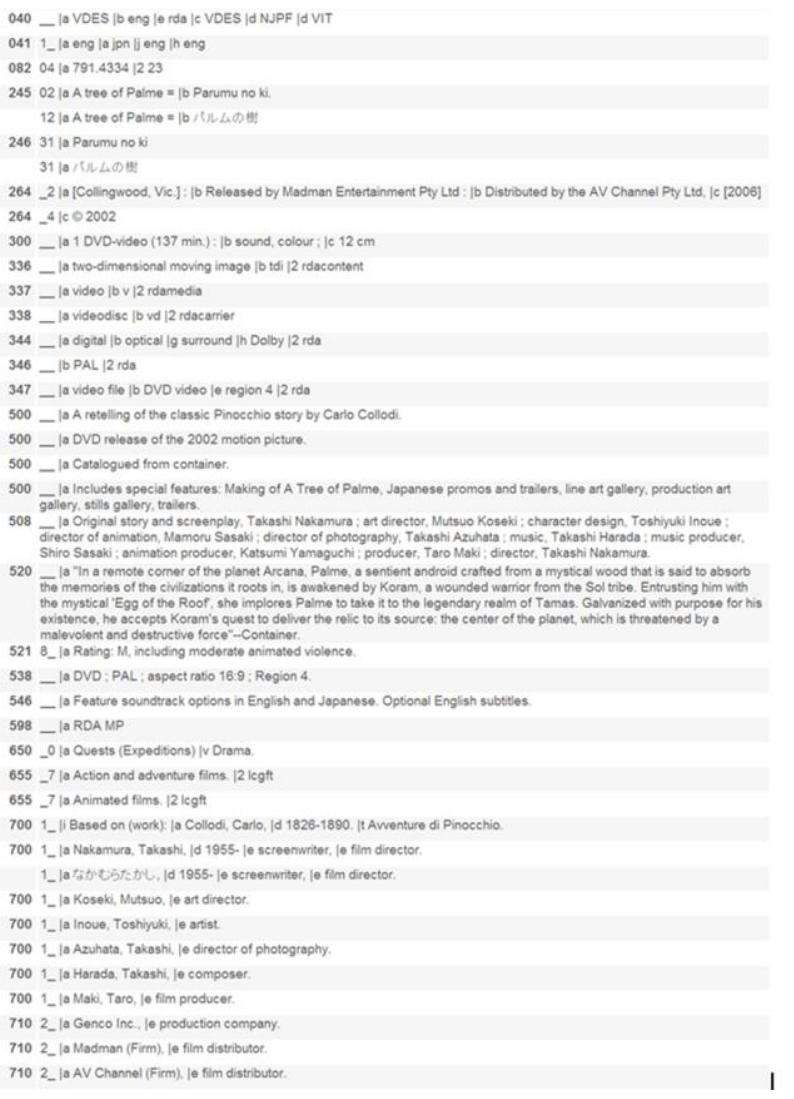

[FIGURE 3. RDA IN PRIMO]

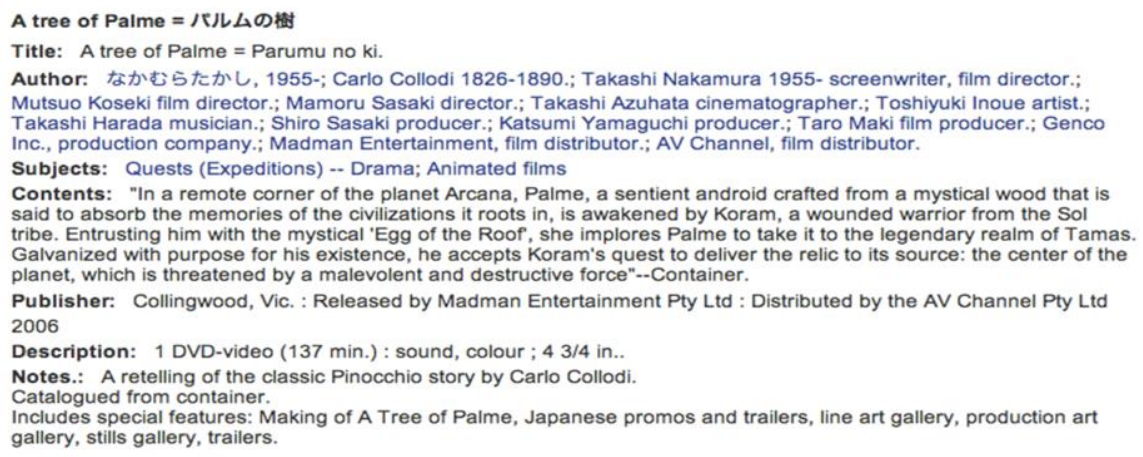


On the basis of these results, it was decided that GMDs were not an issue in the integration of RDA and AACR2 records. Regarding content-media-carrier display, public services staff had not been enthusiastic about the terms when shown RDA records at seminars for non-technical services staff prior to implementation and it seemed best to continue to not display these fields. After migrating to an Alma-Primo configuration, the Library is now more interested in being able to meaningfully manipulate the relationships in RDA records. For example, a facet composed of person-work relationship terms could prove valuable for searchers. The display and index of work-work relationships could also be of value. More local investigation into RDA relationships and Alma-Primo is required, but will most likely be delayed until the Library has more direct configuration access to its discovery layer, which at this time is under vendor control. As pointed out in the PCC Relationship Designator Guidelines Task Group Report ${ }^{27}$, the Library will also need a 'critical mass' of relationship designators in its database before their utility in the discovery layer can be explored.

\section{RDA AUTOMATION}

A high percentage of all cataloging performed at RMIT is copy cataloging. Most cataloging copy enters the database in the form of vendor files, with the remaining copy entering as z39.50 imports of individual records. Copy is checked for accuracy and edited when staff add holdings and items to records, and records requiring significant upgrade are common. As staff already interact with records one by one at the point of adding holdings, 
shortly after implementation LR\&A managers began to explore the possibility of using automation to convert AACR2 records to RDA. Now, acquisitions staff RDA-ify all vendor files before loading records to the database, and an Alma normalization rule (similar in concept to a macro) converts individual records imported via z39.50. Staff who add holdings and items to records check the data elements, make minor adjustments if required, and otherwise bring the records to full RDA by performing the higher-level work of adding and clarifying relationships.

Vendor files are batch processed using Marc Edit's RDA Helper tool and a locally defined task. Marc Edit is free software that is compatible with Windows, Mac, and Linux operating systems. The RDA Helper tool evaluates specific MARC tags to generate and encode RDA elements not already present in a record. It also expands abbreviations using an inbuilt list of abbreviations or a user-defined list ${ }^{28}$. Figures 4 and 5 below show an e-book record before and after the RDA Helper tool (version 5.9.5076.479) is applied.

FIGURE 4. AACR2 RECORD BEFORE RDA HELPER 
=LDR 01724nam 2200433Ma 4500

$=001$ ybp 11136165

$=003 \mathrm{NhCcYBP}$

$=00520131118161931.5$

$=006$ mllllillid

$=007 \mathrm{crll}$

$=008$ 131118s2014||l|enk||l||lo|l||l|000|Olengld

$=02011 \$ a 0124046835$ (electronic bk.)

$=020 \| \$ a 9780124046832$ (electronic bk.)

$=035 \| \$ a(Y B P) 11136165$

$=037 \| \$$ a $515364 \$$ bMIL

$=040 \|$ \$ 2 NhCcYBP\$beng\$cNhCcYBP\$dVIT

$=050$ I 4 \$aTP339\$b.T65 2014

$=08204 \$ a 662.88 \$ 223$

$=1001$ \$ \$aTojo, Seishu.

$=24510$ \$aResearch approaches to sustainable biomass systems $\$$ h[electronic resource] $/$ \$ Seishu Tojo and Tadashi Hirasawa.

$=26011$ \$aOxford, UK; $\$$ aWaltham, MA : \$bAcademic Press, $\$ c c 2014$

$=300 \| \$ a 1$ online resource $(538$ p.) : \$bill. (some col.)

$=506 \| \$ a A c c e s s$ restricted to subscribing institutions.

$=588 \|$ aDescription based on online resource; title from digital title page (viewed on Nov. 18, 2013).

$=598 \| \$ a R D A$ practice.

$=65010 \$ a B i o m a s s$ energy.

$=650 \mathrm{l}$ 10 \$aRenewable energy sources.

$=65510$ \$aElectronic books.

=700 11\$aHirasawa, Tadashi. $=85640$ Suhttp://search.ebscohost.com/login. aspx?direct=true\&scope=site\&db=nlebk\&db=nlabk\&AN=485266\$zAvailable on EBSCOhost eBook Collection $=96011$ \$raaseb\$s 164.93 SuLIBRARY $=961 \mathrm{ll}$ \$cYBP Approval Plan eBooks

\section{FIGURE 5. AACR2 RECORD AFTER RDA HELPER}

$=$ LDR 01724 nam 2200433Mi 4500

$=001$ ybp 11136165

$=003 \mathrm{NhCcYBP}$

$=00520131118161931.5$

$=006$ millilolld

$=007 \mathrm{crlln}$

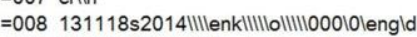

$=020 \| \$ a 0124046835$ \$qelectronic bk.

$=020 \|$ li9780124046832\$qelectronic bk.

$=035 \|$ \a(YBP) 11136165

$=037 \| \$ a 515364 \$$ bMIL

$=04011$ \$aNhCcYBP\$beng $\$ c N h C c Y B P \$ d V I T$ Serda

$=050$ 14\$aTP339\$b. T65 2014

$=082 \quad 04 \$ a 662.88 \$ 223$

$=10011$ SaTojo, Seishu.

$=24510$ \$aResearch approaches to sustainable biomass systems $/$ \$ Seishu Tojo and Tadashi Hirasawa.

$=26411$ \$aOXford, UK; \$aWaltham, MA : \$bAcademic Press.

$=26414 \$ c c 2014$

$=300 \| \$ a 1$ online resource $(538$ pages) : \$billustrations (some colour)

$=336 \|$ Satext $\$ b t x t \$ 2$ rdacontent

$=337 \|$ \$acomputer\$bc\$2rdamedia

$=338 \|$ I aonline resource $\$ b c r \$ 2$ rdacarrier

$=506 \|$ $\|$ aAccess restricted to subscribing institutions.

$=588 \|$ \aDescription based on online resource; title from digital title page (viewed on Nov. 18, 2013).

$=598 \|$ IIRDA practice.

$=650$ lO\$aBiomass energy.

$=65010$ \$aRenewable energy sources.

$=655$ lo \$aElectronic books.

$=7001$ 1\$aHirasawa, Tadashi.

=776 08\$iPrint version:\$aTojo, Seishu. $\$$ tResearch approaches to sustainable biomass systems.\$dOxford, UK; Academic Press, 2014.\$z9781299841130 $=85640$ Suhttp://search.ebscohost.com/login.. aspx?direct=true\&scope=site\&db=nlebk\&db=nlabk\&AN=485266\$zAvailable on EBSCOhost eBook Collection $=960 \|$ IIraaseb\$s 164.93 SuLIBRARY

$=961 \|$ II YBP Approval Plan eBooks 
As shown in the before and after record examples, RDA Helper does the grunt-work of record conversion. RMIT has edited the in-built abbreviation list (a tab-delimited text file) to use the Australian spelling of 'color'. Using the tool the Library could opt to preserve the GMD and add data elements for digital file characteristics.

After the RDA Helper tool is applied to a file, a locally created post-Helper task performs additional transformations. Marc Edit tasks allow users to define a series of manipulations such as adding/deleting fields and subfields, copying field data and changing indicators. Due to the fact that Marc Edit supports the use of regular expressions, tasks can be very powerful transformation tools. The post-Helper task is intended to bring $80 \%$ of all records to the point of requiring the least human intervention. Figure 6 shows the results of the post-Helper task.

FIGURE 6. RDA RECORD AFTER TASK 
$=$ LDR 01724nam 2200433Mi 4500

$=001$ ybp 11136165

$=003 \mathrm{NhCcYBP}$

$=00520131118161931.5$

$=006$ millilolld

$=007 \mathrm{cr} / \mathrm{ln}$

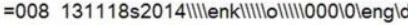

$=020 \| \$ a 0124046835$ (electronic bk.)

$=020$ ॥\$a9780124046832 (electronic bk.)

$=035 \|$ I\$ $(V I T) A l m a$

$=035 \|$ 11 (YBP $) 11136165$

$=037 \| \$ a 515364 \$$ bMIL

$=040 \|$ \$ $a N h C c Y B P \$$ beng\$erda $\$ c N h C c Y B P \$ d V I T$

$=050$ L\$ \$aTP339\$b. T65 2014

$=08204 \$ a 662.88 \$ 223$

$=1001$ \$ 2 Tojo, Seishu, Seauthor.

$=24510$ aResearch approaches to sustainable biomass systems $/ \$ c S e i s h u$ Tojo and Tadashi Hirasawa.

$=26411$ \$aOxford, UK; \$aWaltham, MA: \$bAcademic Press, \$c [2014]

$=26414 \$ \mathrm{C} \odot 2014$

$=300 \|$ \a 1 online resource (538 pages) : \$billustrations (some colour)

$=33611$ \$atext\$btxt $\$ 2$ rdacontent

$=337 \|$ \$acomputer\$bc $\$ 2$ rdamedia

$=338 \|$ \$aonline resource\$bcr $\$ 2$ rdacarrie

$=506 \| \$ a A c c e s s$ restricted to subscribing institutions.

$=58811$ \$aDescription based on online resource; title from digital title page (viewed on Nov. 18, 2013).

$=598 \|$ 11 RDA practice.

$=65010 \$ a B i o m a s s$ energy.

$=65010$ \$aRenewable energy sources.

$=655 \mathrm{lO}$ SaElectronic books.

$=70011$ \$aHirasawa, Tadashi,\$e

=776 08\$iPrint version:\$aTojo, Seishu. $\$$ tResearch approaches to sustainable biomass systems.\$dOxford, UK; Academic Press, 2014.\$z9781299841130 $=85640$ Suhttp://search.ebscohost.com/login. aspx?direct=true\&scope=site\&db=nlebk\&db=nlabk\&AN=485266\$zAvailable on EBSCOhost eBook Collection $=960 \|$ IIraaseb\$s 164.93 SuLIBRARY

$=96111$ \$ Y YBP Approval Plan eBooks

Applying the RDA Helper tool and task to vendor files is a straightforward twostep process that has increased the number of RDA records in the RMIT database. After batch processing with the RDA Helper tool followed by locallycreated "post-helper" tasks, the majority of vendor-supplied copy is RDA compliant and requires minimal editing to make it adequate for local use and for sharing in the Australian co-operative environment. Records meet the Required Data Elements standard issued by Libraries Australia ${ }^{29}$, but RMIT has thus far been unable to share its records with the ANBD and WorldCat. Systems requirements for exporting from Alma to the ANBD are in development by Alma vendor Ex Libris. An RDA automation incubator group is currently investigating methods of validation and scripting for final data clean up while the Library waits to be able to share its RDA records. 
When exploring options for automating mechanical features of the AACR2 to RDA upgrade process, RMIT also considered the global editing capabilities of its library services platform and the use of external software macros. To upgrade individual records within Alma the Library makes use of a local Alma normalization rule. Normalization rules allow record transformations using a vendor-defined set of actions and data elements. Alma normalization rules do not support regular expressions at this time and do not act on punctuation, making them less capable of handling abbreviation expansion and the punctuation preceding MARC coding. Figures 7 and 8 show an Alma record before and after the staff member who is adding holdings and items to the record applies the AACR2 to RDA normalization rule.

\section{FIGURE 7. ALMA RECORD BEFORE NORMALIZATION RULE}

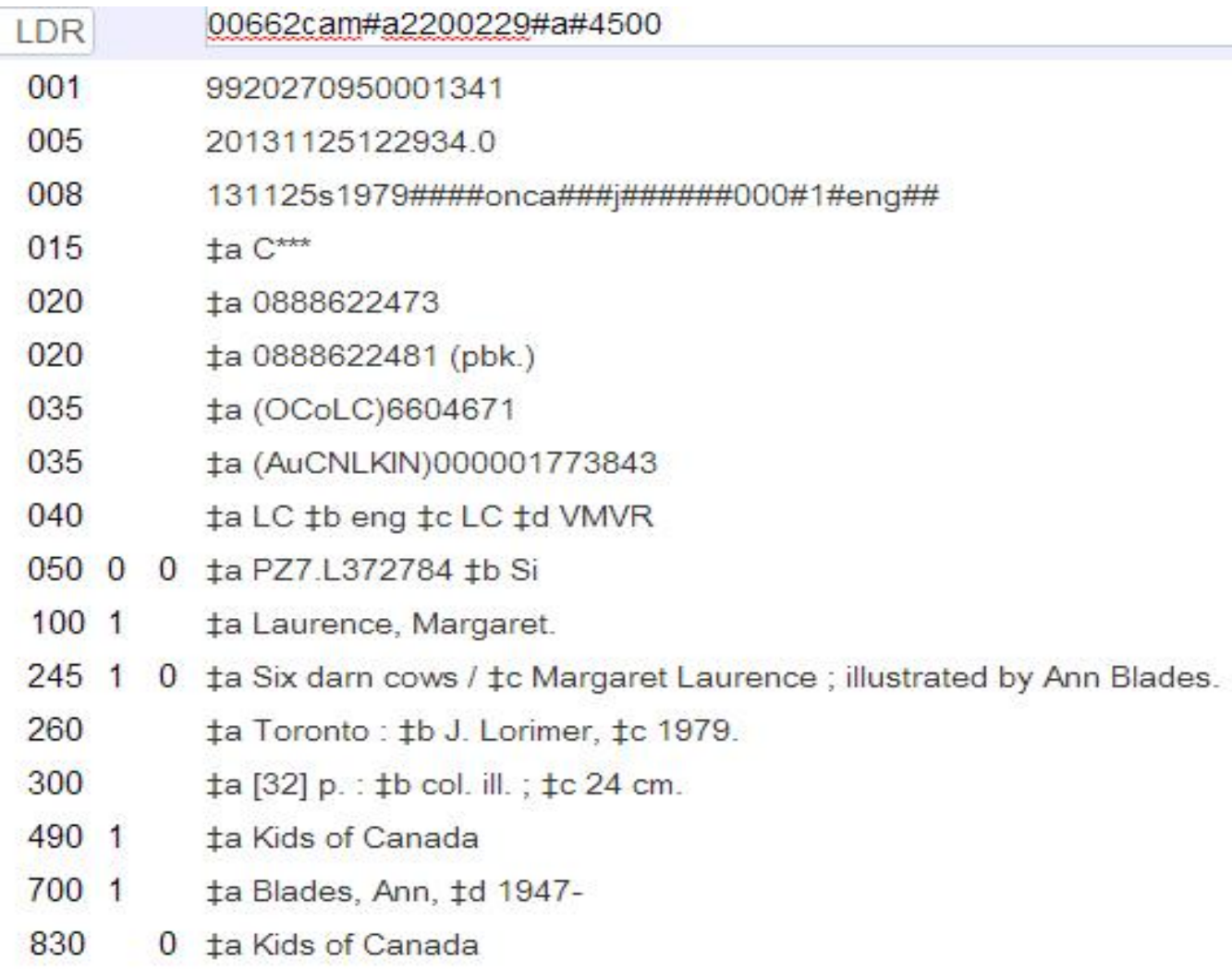


FIGURE 8. ALMA RECORD AFTER NORMALIZATION RULE

\begin{tabular}{|c|c|c|}
\hline LDR & & p0662cam\#a2200229\#i 4500 \\
\hline 001 & & 9920270950001341 \\
\hline 005 & & 20131125122934.0 \\
\hline 008 & & 131125s1979\#\#\#onca\#\#\#\#\#\#\#000\#1\#eng\#\# \\
\hline 015 & & $\ddagger a C^{*+*}$ \\
\hline 020 & & ‡a 0888622473 \\
\hline 020 & & 士a 0888622481 (pbk.) \\
\hline 035 & & fa (OCoLC) 6604671 \\
\hline 035 & & ‡a (AuCNLKIN)000001773843 \\
\hline 035 & & ‡a (VIT)Alma \\
\hline 040 & & 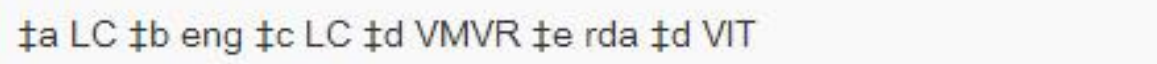 \\
\hline 050 & 00 & ‡a PZ7.L372784 ‡b Si \\
\hline 100 & 1 & fa Laurence, Margaret. fe author \\
\hline 245 & 10 & ‡a Six darn cows / $\ddagger c$ Margaret Laurence ; illustrated by Ann Blades. \\
\hline 264 & 1 & 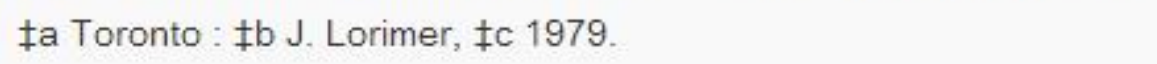 \\
\hline 264 & 4 & $\pm c(c)$ \\
\hline 300 & & ‡a [32] pages. : $\ddagger b$ colour. illustrations. ; $\ddagger c 24 \mathrm{~cm}$. \\
\hline 336 & & $\ddagger a$ text $\ddagger \mathrm{b}$ txt $\ddagger 2$ rdacontent \\
\hline 337 & & $\ddagger$ unmediated $\ddagger \mathrm{b} \mathrm{n} \ddagger 2$ rdamedia \\
\hline 338 & & $\ddagger$ volume $\ddagger \mathrm{b} \mathrm{nc} \ddagger 2$ rdacarrier \\
\hline 490 & 1 & ła Kids of Canada \\
\hline 598 & & ła RDA practice \\
\hline 700 & 1 & ‡a Blades, Ann, ‡d 1947- \\
\hline 830 & 0 & ła Kids of Canada \\
\hline
\end{tabular}

RDA automation has allowed RMIT to meet implementation goals regarding contributions to the ANBD (when contribution becomes possible) and record upgrading. RDA automation has also allowed the Library to revise its goal of accepting clean AACR2 copy as it is by largely automating AACR2 to RDA upgrading. Automation has allowed a rapid increase in the number of RDA records populating the Library database. Although designing the local Marc 
Edit task and normalization rule required an outlay of staff time and effort, the investment is regarded as a successful component of the Library's RDA implementation.

\section{LESSONS LEARNED}

Some eight months after formal RDA implementation at RMIT, the Library has had opportunity to reflect on the training and implementation process without yet being able to conduct a formal assessment. An anonymous feedback form for staff to leave comments or complaints has not been popular, but staff have verbally expressed an appreciation for the small group training model and a desire to continue the small group design in future RDA sessions. From the staff perspective, small groups were a successful component of training, and the small group training model permitted training materials and delivery to be adjusted to suit a particular group's learning needs. RDA training in small groups worked well for RMIT in terms of learning outcomes and staff satisfaction. It is recommended that a small group training model be used when institutions have the capability to do so.

The FRBR focus of RDA training is also seen as a vital component of the Library's implementation and RMIT's experiences suggest that regardless of original or copy cataloging roles, FRBR training is beneficial. The language of cataloging at the Library has shifted from AACR2 to RDA, and FRBR training has proved beneficial in the post-implementation RDA automations that the Library has enacted. All staff interacting with not-quite RDA records are able to record relationships that are a key feature of RDA and the FRBR 
conceptual model underlying RDA. However, the effects of not understanding the complex FRBR conceptual model are stressful for staff having difficulties, and whether or not FRBR understanding fuels RDA understanding remains an area for further exploration.

RDA training as conducted at RMIT also showed a gap in Toolkit training and how learners would need to interact with the Toolkit in order to create RDA records. The Library's experiences with publication details and policy development showed that more structured training on use of the Toolkit would have been useful for learners at the very early stages of training. Although the NLA RDA training materials ${ }^{30}$, like Library of Congress training materials ${ }^{31}$, included sections on how to use the Toolkit to gather related RDA instructions, not enough emphasis was placed on this during RMIT's RDA training. Trainers were mistaken in their belief that the minimal Toolkit practice and exposure which staff gained during training, followed by enforced use of the Toolkit during formal peer review, would be enough for staff to develop Toolkit skills. It is recommended that RDA training include structured Toolkit orientation and practice in following Toolkit hyperlinks to gather decisionmaking instructions.

The use of automation to bring incoming copy as close to RDA as possible has been a successful component of the Library's implementation, and it is recommended that institutions investigate the feasibility of building RDA automation into their own workflows. Machines can do much of the upgrading of AACR2 copy to RDA, and most if not all systems have global editing 
capabilities. Batch conversion can also be done external to the system using MarcEdit software.

The staff training model included a desire to develop workflow flexibility, and has proven to be successful in relation to RDA automation at the Library. A number of different roles now incorporate final editing of batch processed records and high-level relationship work. At the same time, as roles have evolved under Alma the staff training model has not proven useful for some staff. Some staff roles in Alma do not yet incorporate RDA. These roles are primarily in the E-resources and Serials team, where staff deal mostly with the acquisition, licensing and access aspects of electronic resources. If these roles come to require RDA involvement in the future re-training will be required. Institutions may find it useful to consider staff roles in relation to RDA goals in the short and long term when deciding on training and implementation staffing. A staggered training scenario would have better served RMIT.

\section{CONCLUSION}

RMIT chose to implement RDA at a time when significant resourcing was directed toward a system change and workflows were in transition. Workflows in flux and a blended staffing model led to training for all 25 technical services staff. RDA training was conducted internally and in small groups. The small group model has since received positive staff feedback and is considered a successful implementation strategy. Training had a strong focus on FRBR rather than comparison between RDA and AACR2, but omitted authority 
components of RDA. A FRBR focus developed staff familiarity with the language of RDA and possibly aided in Toolkit orientation. It is not clear whether the FRBR focus increased overall understanding of RDA, and whether or not understanding the FRBR conceptual model is required for professional use of RDA. During RDA training it became clear that the boundaries between description and encoding were not understood, and that a surprising number of catalogers were guided by the work of their peers rather than by the Toolkit when creating RDA records. An intensive process of peer review pushed staff into using the Toolkit as much as possible due to reports of common initial difficulties with the Toolkit, and has helped shift reliance on examples over principles. Managers perceive peer review as a beneficial element of the Library's implementation but have mixed opinions on how peer review could have been deployed more effectively. After formal training the RDA trainers identified a training gap when staff demonstrated difficulty in consistently applying RDA 2.8 guidelines on recording place of publication and publisher. A greater emphasis on how to use the Toolkit to gather decision-making instructions during training could have prevented this gap, which was addressed through later policy statements at RMIT. Institutions who are yet to implement RDA may learn from RMIT's training error and provide more Toolkit practice as part of formal RDA training.

Local RDA policy will be an element of any implementation, chiefly due to the role of cataloger's judgment in RDA. RMIT developed local policy as implementation proceeded rather than determining the policy beforehand. Developing policy 'on the go' required continuing trainer involvement in 
gathering and coordinating information to support policy decisions. Posttraining and implementation policy development had the advantage of highlighting the most relevant policy decisions for Library staff, and incited discussion on the role of cataloger's judgment in RDA. RDA has not created systems issues in the Library's Alma-Primo configuration, although more investigation into meaningful display and faceting of RDA relationships in the discovery layer is desired. Populating the library's database with RDA records is done at an increased pace through post-implementation automation. Vendor files are upgraded from AACR2 to RDA in batch processes using Marc Edit software, while individual records are candidates for global editing within the Alma library services platform.

Institutions that are looking into the future to decide the timing of their own implementations may have difficulty identifying the most suitable time to move forward. RMIT's experiences show that stability and in-depth preparations are not requisite features of a successful RDA implementation. For those who are yet to implement RDA, there needn't be one suitable time for implementation. With implementation goals defined, small training groups, and responsive (or prior) policy development, any time may be a good-enough time to implement RDA.

1. Australian Library and Information Association, "Accredited Courses for Working in the Sector," (2012), http://www.alia.org.au/employment-and careers/courses-eligible-alia-membership (accessed November 7, 2013). 
2. Stalberg, Erin, "RDA in Context," [presentation at RDA Implementation Experiences: an OCLC Webinar on October 16, 2013] (accessed November 2, 2013).

3 . Maurer, Margaret, "RDA Travelogue," [presentation at RDA Implementation Experiences: an OCLC Webinar on October 16, 2013] (accessed November 2, 2013).

4. National Library of Australia, "Australian Training Materials," (2012), http://www.nla.gov.au/acoc/training-materials-for-resource-description-andaccess (accessed November 4 2013).

5. Cronin, Christopher, "From Testing to Implementation: Managing FullScale RDA Adoption at the University of Chicago," Cataloging \& Classification Quarterly 49, no. 7-8 (2011): 626-646.

6. Shieh, Jackie, "Participation in the U.S. RDA Test Program Helped Transform Work Habits at George Washington University Libraries," Cataloging \& Classification Quarterly 49, no. 7-8 (2011): 647-654.

7. Schiff, Adam, "Comparisons Between AACR2 and RDA. Part 1: Description," (2011), http://faculty.washington.edu/aschiff/OCLCPresentationPart1-WithNotes.pdf (accessed November 3, 2013).

8. Kiorgaard, Deirdre, "Resource Description and Access, a National Library of Australia Staff Paper," (2009), http://www.nla.gov.au/openpublish/index. php/nlasp/article/viewArticle/1420 (accessed November 2, 2013) .

9. Hitchens, Alison and Symons, Ellen, "Preparing Catalogers for RDA Training, Cataloging \& Classification Quarterly 47 no. 8, (2009): 691-707. 
10. Mitchell, Erik, "Is RDA Ready?: An Analysis of Case Studies in RDA Testing," Technical Services Quarterly 30 no. 1, (2012): 70-82.

11. Loesch, Martha Fallahay, "RDA in Perspective: How to Use the Library Literature to Your Advantage," Technical Services Quarterly 30 no. 1, (2012): 1-14.

12. Joint Steering Committee for the Development of RDA: Resource Description and Access, "Frequently Asked Questions", (2012?), http://www.rda-jsc.org/rdafaq.html\#4-5 (accessed January 3, 2013.)

13. Stalberg, Erin, "RDA In Context."

14. Ibid.

14. PCC-SCT RDA Records Task Group, "RDA Record Examples,” (2012), http://www.loc.gov/catworkshop/RDA\%20training\%20materials/SCT\%20RDA \%20Records\%20TG/index.html (accessed November 3, 2013).

16. Mitchell, Erik, "Is RDA Ready?,” 7.

17. Grant, Carl, "The Future of Library Systems: Library Services Platforms," Information Standards Quarterly 24 no. 4, (2012): 7.

18. El-Sherbini, Magda, RDA: Strategies for Implementation (Chicago: ALA Editions, 2013), 62-64.

19. Cronin, Christopher, "From Testing to Implementation," 633.

20. Maurer, Margaret, "RDA Travelogue”.

21. National Library of Australia, "Australian Discussion List on RDA," (2011?), http:// www.nla.gov.au/acoc/communication-discussion-questionsand-feedback (accessed November 2, 2013). 
22. Joint Steering Committee for the Development of RDA: Resource Description and Access, "RDA-L" (2006?), http://www.rdajsc.org/rdadiscuss.html (accessed November 23, 2013).

23. Joint Steering Committee for the Development of RDA: Resource Description and Access, "Working Documents," (last updated August 2013), http://www.rda-jsc.org/working1.html\#constituency (accessed November 23, 2013)

24. Mitchell, Erik, "Is RDA Ready?," 7.

25. Loesch, Martha Fallahay, "RDA in Perspective." 5.

26. Cronin Christopher, "From Testing to Implementation," 633.

27. "PCC Relationship Designator Guidelines Task Group Report" (13 March 2013 revision), http://www.loc.gov.aba/pcc/rda/RDA\%20Task\%20group s\%20and\%20charges/PCC-Relat-Desig-TG-report.rtf (accessed November 24, 2013).

28. Reese, Terry, "Dragging Old Data Forward: Finding Yourself an RDA Helper", (2013), http://www.slideshare.net/reese_terry/dragging-old-dataforward-finding-yourself-an-rda-helper (accessed November 27, 2013).

29. National Library of Australia. Libraries Australia, "Required Data Elements", (2013), http://www.nla.gov.au/librariesaustralia/services/ cataloguing/standards/required-data-elements/ (accessed 24 November, 2013).

30. National Library of Australia, "Australian Training Materials" 
31. Library of Congress, "Using the RDA Toolkit," (2012), http://www.loc.gov/aba/rda/pdf/ToolkitCourse.pdf (accessed 24 November, 2013). 